\title{
A imaginação sociológica e questões críticas em C. Wright Mills: pontos de referência ao papel do educador
}

\author{
Gastão Octávio Franco da Luz ${ }^{*}$
}

\section{Apresentação}

É exaustiva, na contemporaneidade, a abordagem do último século em função da velocidade das mudanças. Grosso modo, é possível identificar três tendências básicas no modo de fazê-la:

a) uma que pretende a interpretação mais otimista, por meio da qual tudo o que se vem constituindo em crise deve ser compreendido como oportunidades. Nesta visão toffleriana de mundo, funciona a lógica da oportunização de iniciativas, uma vez que pressupõe quase que bastar um estado de alerta, que uma vez bem associado a "competências em prontidão", deve garantir o surgimento de espaços de atividades e ganhos, pois deste modo saber-se-ia "tirar vantagens" das transformações;

b) uma segunda perspectiva emerge nos discursos patronais que, marcados por uma atmosfera de pretensa neutralidade, informam sobre a naturalidade dos adventos, sobre a inevitabilidade dos fatos e, sob a égide de um determinismo tácito (no que então, se fazem acompanhar por cientistas, técnicos e tecnocratas), sobre a inexorabilidade do progresso científico, em relação ao qual só restariam adequações e adaptações, com inevitáveis resultantes na ordem das perdas e ganhos;

c) por último, encontram-se os trabalhos que recolocam a questão das mudanças numa concepção de exigências mais amplas e, certamente, mais ricas em dimensionalidade - refiro-me aos que, em seus recortes de

* Professor do Departamento de Métodos e Técnicas da Educação da Universidade Federal do Paraná. 
análise, não perdem a perspectiva das pessoas, em especial dos que possam ser chamados de pessoas comuns. E é neste ponto que, confrontada a última com as duas anteriores formas de se interpretar os acontecimentos de nosso tempo, repousa uma sutil porém determinante diferença de se discutir a(s) crise(s) - a aceitação de se ter gente enquanto paradigma.

A ótica humanista para a análise das mudanças (ou revoluções?) não se prende somente ao resgate da questão ética, moral, das conseqüências dos processos decisórios nos âmbitos da economia, das implementações tecnológicas etc., sobre a vida das pessoas que na sociedade não se apercebem de como foram envolvidas no fluxo das construções históricas. Ela é importante mesmo no trato racional que se deve dar no decorrer dos estudos.

Assim é que, por exemplo, chama a atenção o fato de o processo de globalização, que caracteriza o final do século XX, enquanto se revela como foco de tensão pela incapacidade conjunta das instituições públicas e do coletivo das pessoas àquela se acomodarem, na instância do privado, o comportamento humano revela muito melhor capacidade de adaptação ao mundo televisivo por satélite, ao correio eletrônico, aos pacotes turísticos internacionais ou ao emprego transoceânico. Por outro lado, como outra forma de transformação, a desintegração dos velhos padrões de relacionamento social humano e, como resultante, a quebra dos elos intergerações, o que vale dizer entre passado e presente, geraria um individualismo associal absoluto, seja nas ideologias oficiais, seja nas não-oficiais. Este social, formado por indivíduos egocentrados sem interconexões, cuja meta se limita à busca da própria satisfação (lucro, prazer...) afinal sempre fez parte dos pressupostos da teoria capitalista. Mas em sua gênese não foi assim que a revolução capitalista se processou.

$\mathrm{Na}$ aparente contradição da sociedade burguesa, não se constitui em "enigma sociológico" a introdução de um individualismo radical na economia, despedaçando todas as relações sociais ao fazê-lo, ao mesmo tempo em que sempre temeu o individualismo experimental radical na cultura, no comportamento ou na moralidade. Para tanto, com eficácia construiu uma economia industrial baseada na empresa privada, combinando-a com motivações extramercado, como a ética protestante, com a noção de abstenção da satisfação imediata, com a concepção ética do trabalho árduo, com as noções de dever e confiança familiar... Mas, neste final de século e milênio, o processo capitalista acaba corroborando o que já havia sido prognosticado pelo Manifesto Comunista e por outros profetas da desintegração dos valores: hoje encontramo-nos à deriva, configura- 
mos uma "era de incertezas", frente à qual não dispomos de esquemas de referência (Hobsbawn, 1995; p. 24-25).

Como se não mais fossem interessantes ou convenientes, os laços valorativos se partiram e a questão não é mais discutir a velocidade das mudanças, mas sim a violência da velocidade de mudanças, seus fatores causais, os nossos papéis frente à realidade e as perspectivas de estudo. Para tanto, uma apreciação de A imaginação sociológica, de C. Wright Mills (1972), em dois capítulos da obra, "A promessa" e "Da razão e liberdade", constitui-se em um exercício de observação da perenidade de relevância das reflexões do autor, bem como em fundamentação argumentativa capaz de fazer frente aos discursos "objetivos" e/ou "neutros", ao redor das questões da atualidade mundial, dos papéis da Ciência Social, das pessoas enquanto componentes ativos do processo histórico e, destacadamente, do que cabe aos campos da educação e da cultura.

Para a consecução desta contribuição, quatro abordagens passam a ser feitas: qual o significado de imaginação sociológica; que relações existem entre indivíduo e sociedade em Mills; qual a crítica fundamental à Ciência Social contemporaneamente e quais as tarefas básicas para a Ciência Social em nossos dias.

\section{O aforismo da imaginação sociológica}

Numa teoria é impossivel aceitar pequenas grandezas observáveis. Ao contrário, é a teoria que decide o que se pode observar:

A. Einstein

(...) e devemos lembrar que o que observamos não é a natureza mesma, mas a natureza imposta por nossa maneira de suscitar as perguntas.

W. Heisenberg

(apud Watzlawick, 1994, p.103)

Um dos grandes dramas das pessoas comuns se localiza na não-superação de suas preocupações e angústias, cujas origens não thes são claras. Quando tentam mobilizações, tendo em vista um fazer, uma ação aparentemente solucionadora, percebem-se circunscritos, limitados por 
órbitas privadas, dentre as quais suas vidas transcorrem. Configura-se, deste modo, um estado permanente de confinamento, sem que as pessoas compreendam que este já é um segundo momento do processo, pois, inicialmente, elas já foram excluídas de muitas coisas. Entendidos os movimentos de transformações sociais que agitam o planeta como também determinadores de uma falsa impessoalidade dos acontecimentos nas estruturas sociais, elas pouco se dão conta que as mesmas promovem a transmutação de seus papéis sociais de modo profundo e, por vezes, definitivo. Não dispondo de qualidades intelectuais básicas para a interpretação deste estar à deriva nas transformações históricas e contradições institucionais, não percebem as reciprocidades entre pessoas e sociedade, entre biografia e história, entre o eu e o mundo. (Mills, 1972, p. 9-10)

A questão, portanto, circunscreve-se no discernimento das inter-relações que se estabelecem entre o público e o privado, que numa civilização estruturada sob paradigmas polarizadores, duais, revela-se como absolutamente coerente, porém eivada de variáveis problematizadoras e por vezes mortais.

Cabe aqui a lembrança de que o cidadão representa uma criação do Estado, o qual sempre irá moldá-lo à luz de seus interesses. Sendo assim, a cidadania passa a ser vista como um duplo na identidade do homem: na esfera individual, cada pessoa é una e inigualável; na esfera pública, cada um é um cidadão, em tese igual a todos os outros assim vistos. Esta prerrogativa, de cunho principalmente jurídico, define condicionantes e, como todo processo de identificação, é uma relação de poder, estabelecida pelas figuras do identificado e a ação do outro, o identificador, como afirma Gianotti. (Ferreira, 1993, p. 20-21)

Considerado o fato de vivermos um momento em que as histórias pessoais são regidas pela história do mundo globalizado, as sutis (ou, por vezes, flagrantes) interligações que compõem a rede de recíprocas influências, localizam-se no ponto cego da maioria dos homens e mulheres, os quais transmutam-se em co-partícipes de uma peça, mas alienados de seus papéis, sem compreensão da própria cena em que estão mergulhados. Crise passa a ser a palavra-chave - sofre-se, mas não se sabe porque, desde onde ou quando. É agravante o caráter múltiplo da crise.

Nós estamos num mundo que vive uma tríplice crise, crise política, isto é, uma posição de incerteza entre a democracia e a não-democracia; crise econômica, porque são sistemas em que a economia do Estado está desburocratizada e centralizada. É um sistema onde as pessoas sonham com outra vida, com outra 
economia, mas dispondo de um mínimo de segurança. Elas estão num intermediário. Não têm nenhuma das vantagens esperadas de um novo mundo e perderam toda a segurança do mundo precedente. Donde, um fenômeno de desânimo extraordinário.

(Morin, 1993, p. 13)

Assim, o que preocupava Mills, já no início da década de 50, revelase hoje mais do que um alerta corretamente preditivo, mas que se agravou e aprofundou o estado de sensação de armadilha que toma de assalto a maioria dos cidadãos. É sempre importante lembrar que as análises e chamadas de atenção referentes à opção civilizatória que exercemos são contemporâneas ao próprio surgimento da forma de pensamento que nos levou ao lugar em que estamos. As noções de "progresso", "modernidade", "evolução", desde o seu nascedouro, tiveram suas antíteses profetizadas, sem que o diálogo, ou a parada para possibilidades de revisão conseguissem acontecer.

Enquanto aquelas noções surgiram como questões predominantemente racionais e intelectuais, determinam-se os invariantes de um processo histórico unilateral que agora atinge um estado alarmante e tão paradoxal que beira a insanidade. Se por um lado podemos controlar os pousos suaves de espaçonaves em planetas distantes, não temos idéia de como controlar as diferentes formas de poluição; se hoje somos capazes de propor comunidades utópicas em colônias espaciais, não imaginamos ao menos como administrar nossas cidades. (Capra, 1988, p. 39)

Este enredar-se planetário, para Mills representa a criação de uma ilusão de impessoalidade das mudanças que se passam na malha de estrutura social - quando as pessoas percebem alguma coisa, elas mesmas já mudaram nos seus desempenhos sociais. Este não-se-dar-conta da mutação pessoal soma-se à incapacidade de descoberta das próprias possibilidades de escolha, frente ao tipo de evolução histórica de que poderiam participar. Assim, somos transformados à revelia de nossas consciências e matamos na potencialidade as nossas oportunidades de exercício de atores frente aos acontecimentos.

Corrobora esta noção de rede social do autor a contribuição de Lévy no que diz respeito à concepção de ecologia cognitiva, por meio da qual se desenvolve a tese da necessidade de ultrapassarmos a noção de sujeito e objeto, quando das idéias de sujeito e sistema. Para ele, inteligência ou cognição, resultam de redes complexas, nas quais interage grande número de atores humanos, biológicos e técnicos. Assim compreendido, não sou eu que sou inteligente, mas eu com o grupo humano de que faço parte, 
com todo o meu aparato civilizatório. "Fora da coletividade, desprovido de tecnologias intelectuais, eu não pensaria. O pretenso sujeito inteligente nada mais é que um dos microatores de uma ecologia cognitiva que engloba e restringe." (Lévy, 1993, p. 135)

Ora, se inventamos a realidade a partir de nossas configurações teóricas sobre o nosso imediato e sobre o mundo; se de fato são nossos óculos sociais, que resultam de uma produção coletiva, que definem o nosso modo de observar $e$ que nos oportunizam os significados da vida, dadas as circunstâncias anteriormente elencadas, não é surpreendente que pessoas comuns percebam sua incapacidade de enfrentar horizontes mais amplos, ou deixem de compreender o sentido de seu tempo e de suas existências. A rigor, em defesa do eu, tornam-se moralmente insensíveis, lutando para permanecer como seres particulares e com a sensação de confinamento. (Mills, 1972, p. 11)

Mills levanta a questão igualmente crucial da mudança de mãos do poder, com os meios de autoridade e violência se tornando totais no alcance e burocrático na forma. Sobre esta marcante peculiaridade do século XX, diferentes autores corroboram o sentido dado pelo autor em análise.

As civilizações se marcam, dentre outras prerrogativas, pelas respostas que dão às solicitações do que pode ser chamado imagens reguladoras, que em cada época regulam os parâmetros do que se entende por ser humano. Assim é que sempre necessitamos evocar os pensares dos sábios, dos santos ou dos heróis de cada tempo, os quais, além de justificarem a nossa humanidade, fornecem às multidões ("menores" que eles) as razões de ser e de esperar.

Porém, a nossa prova de existência, contemporaneamente, no mais das vezes passa pela substituição daquele tipo de imagem reguladora, ou pelo vazio de sua ausência, ou pela imagem corrompida. Personagens que se pautaram pela performance da demência, pelo uso abominável dos campos de concentração, pela recorrência aos massacres, pela morte mesma da individualidade e do senso de coletividade, neste século, em especial, nortearam tendências, movimentaram populações e exércitos, marcando o século XX como um período digno de um leviatã. Como compreender que personagens como Adolf Hitler ou Joseph Stalin hajam conseguido impor-se (em plena vigência da racionalidade) como líderes de milhões? Como deixar de pensar que, se Hitler desapareceu ao debaterse com os que the eram mais fortes, Stalin morreu no leito, sendo necessários anos para a desmistificação, mas que ainda não é plena, dado o número significativo de admiradores? (Japiassu, 1975, p. 21) 
Uma alternativa para responder a estas interrogações passa pela questão da informação, de como ela é gerada, como é posta a circular e de que modo se dá a sua assimilação e decodificação. A gerência da propaganda, em tempos de pânico e desnorteamento, ajuda a trabalhar com aqueles fatos, conforme se abordará adiante neste documento.

A questão da autoridade e da violência, necessita ser também discutida com base no entendimento de que em tempos de especialismo, ninguém é responsável por nada. Em um mundo de especialistas, todos "cumprem ordens", que se perdem nas tentativas de se descobrir as fontes, cada vez que nos propomos a perseguir sua hierarquia. Hiroshima ou corrupção no sistema bancário, massacres infanto-juvenis ou poluição de mananciais, cobranças indevidas nas taxas públicas ou tortura durante regimes de exceção, quando localizados os suspeitos, todos "cumpriram ordens".

Quando se perde a visão global do contexto, quando todos os sistemas fundamentais da civilização (educação, informação, tecnológico) são apreciados de modo fragmentado, mesmo que se atue intelectualmente sob a máxima de que "o todo se repete nas partes", se meus óculos sociais não descortinam holisticamente a paisagem, o conjunto inteiro não se desvelará jamais. Daí que também vivemos o tempo das impunidades.

Autoritarismo e violência, destacados por Mills, não se operam em nossas vidas, apenas em relação ao poder estatal com que convivemos. O deficit democrático que se instaurou sobre as pessoas e que nos faz cada vez mais alijados dos direitos de pensar, de falar e de agir, tem no estafe que compõe boa parte de nossa intelligentia fortes coadjuvantes de militares e políticos - os cientistas e tecnólogos, em preocupante monta.

Quando em Paris mais de trezentos hemofílicos foram levados a óbito, devido à administração de sangue contaminado pelo HIV, com o conhe-cimento de autoridades científicas francesas, além de haver sido impossível definir as responsabilidades, que obviamente iam de laboratoristas ao Gabinete, a ocorrência trouxe à tona a questão de o cidadão comum não ter conhecimento dos grandes problemas globais e a retórica dos especialistas e técnicos que argumentam da impossibilidade de as pessoas comuns conhecerem os assuntos da ciência e da tecnologia. Evidentemente, não se trata de tornar o homem comum competente nas nuanças dos laboratórios, mas sim conhecedor das idéias fundamentais. Não faz falta o saber específico que associa Engenharia Genética e planejamento familiar - mas a discussão sobre se temos ou não o direito de escolher o sexo das crianças, se devemos ou não manipular genes com vistas a se- 
letividades, ou sobre os critérios de segurança a que tem direito um paciente vinculado a um banco de sangue, não são instâncias de domínio exclusivo de um mandarinato. Estas idéias podem estar à disposição de todos. Estes são problemas que apresentam domínio hegemônico somente por um viés de autoridade e pela violência da detenção do saber, principalmente e porque todos os problemas fundamentais, dizem respeito às idéias. (Morin, 1993, p.18)

Mas autoridade, violência, hegemonia de conhecimento e burocratização ainda se associam às incertezas e enganos de nossa elite científicotecnológica. Quando em 1979 o Washington Post publicou uma história entitulada $O$ armário de idéias está vazio, pelo qual eminentes cientistas admitiam sua retumbante incapacidade de resolver os mais urgentes problemas norte-americanos, ficou instalada a crise de idéias no seio da comunidade detentora das idéias! Todos os entrevistados, entretanto, não se deram conta de tal crise, tanto que argumentaram como argumentam as pessoas comuns de Mills, atribuindo suas dificuldades às "novas circunstâncias" ou ao "curso dos acontecimentos", senso comum aos mais comuns dos mortais. Ora, os problemas são sistêmicos, ou seja, intimamente ligados e interdependentes, escapando ao âmbito das metodologias fragmentadas, usuais no mundo acadêmico e na instância governamental. Aquela argumentação tão somente limita-se a transferir as dificuldades de um lugar a outro, na complexa rede de relações sociais e ecológicas.

Uma resolução só poderá ser implementada se a estrutura da própria teia for mudada, porque envolverá transformações profundas em nossas instituições sociais, em nossos valores e idéias. Quando examinamos as fontes de nossa crise cultural, ficará evidente que a maioria de nossos principais pensadores usa modelos conceituais obsoletos e variáveis irrelevantes. (Capra, 1988, p. 23)

Retomando a questão das informações e sua consideração enquanto foco de crise no presente, Mills critica as tendências que já então reduziam o tema à democratização do saber, seja pela via tradicional da transmissão, seja por suas variantes que, pelo argumento do mero "fazer saber", não se libertam da metáfora do conhecimento como "balde", para a qual o ensino, por exemplo, se planeja com a ótica da vazão.

A rigor, diz o autor, a informação veiculada massiçamente e de modo massificado domina a atenção e esmaga a capacidade de as pessoas exercerem a assimilação. O saber produzido e acumulado não é exigente apenas de "habilidades da razão", mas também, e 
fundamentalmente, é uma questão de qualidade de espírito, que auxilia na utilização da informação e no desenvolvimento da própria razão; deste modo, desperta-se a percepção para o que se passa no mundo e dentro de cada pessoa.

Nesta perspectiva, Mills encontra suporte em diferentes pensadores, representantes de diversas áreas do saber, que na atualidade corroboram e propugnam as mesmas hipóteses dentro da mesma epistéme.

Discutindo a questão da informação sob o ângulo escolar, Jean Foucambert propugna uma verdadeira política de leiturização das pessoas, partindo do pressuposto de que nos encontramos em tempos para os quais não mais é suficiente alfabetizar as pessoas, tornando-as apenas leitores: hoje exige-se a formação de leiturizadores.

Pesquisador e especialista da leitura, Foucambert recomenda uma agilização do ensino pela leiturização, a qual exige a mobilização, a ativação e o desenvolvimento consciente dos meios de que dispomos (estruturais, materiais e humanos), tanto para a redução dos índices de analfabetismo, como para qualificar as pessoas a lerem com suspeição, cujo pressuposto não é o de que todos os discursos são mal-intencionados - embora muitos o sejam -, mas sim porque todos os discursos têm mais de uma intenção. Deste modo, espera-se formar o leiturizador, aquele sujeito que além de "viajar" nas asas dos personagens, lê, nas entrelinhas, o que 0 autor deveria ter dito e não disse.

Estabelece, assim, o que ele chama de $o$ estatuto do leitor:

Ser leitor é querer saber o que se passa na cabeça do outro, para compreender melhor o que se passa na nossa. Essa atitude, no entanto, implica a possibilidade de distanciar-se do fato, para ter dele uma visão de cima, evidenciado de um aumento do poder sobre o mundo e sobre si mesmo, por meio desse esforço teórico. Ao mesmo tempo implica o sentimento de pertencer a uma comunidade de preocupações que, mais que um destinatário, nos faz interlocutor daquilo que o autor produziu. Isso vale para todos os tipos de texto, seja um manual de instruções, seja um romance, um texto teórico ou um poema. (Foucambert, 1994, p. 30)

Este estatuto antecede o saber. Desenvolvendo o poder sobre si e sobre o mundo, a criança, por exemplo, encontra a escrita e aprende a ler (leiturizar). Essa relação entre poder e escrita proporciona às pessoas as condições que autorizam aquele encontro. Entendendo-se que todo aprendizado é uma resposta a um desequilíbrio, o ambiente alfabetizador, 
rico de recursos, exige ações de ensino que estimulem a atividade reflexiva sobre as estratégias efetivamente aplicadas para a resolução dos problemas levantados no texto. Com isto, está-se diante de uma abordagem metaléxica, que faculta ao sujeito avançar suas estratégias de questionamento, construindo-as como um sistema, organizando redes que se abrem para outras hipóteses e outros índices.

Do encontro que promovo entre Mills e Foucambert, é possível avançar para outros enfoques que reforçam a idéia de compreensão do cenário histórico e seu significado para a vida íntima das pessoas, tendose a questão da informação enquanto foco central.

O desenvolvimento incontrolado da técnica, quando se tem como pano de fundo uma comunidade subjugada, isenta daquela qualidade de espírito de que se tratou anteriormente, favorece a eventualidade despótica dos mass media. Dos "escritórios oficiais de propaganda", à criação de mitos e heróis que, por mais medíocres e superficiais que sejam, servem aos fins e serviços do poder de mando, aprofundando a alienação. Assim, fica-se diante não somente de uma patologia do saber, mas de uma patologia da existência individual e coletiva, de modo a estabelecer a deficiência ontológica, geralmente mortal à civilização. Novamente é a questão, no campo da informação, dos riscos da quebra de valores, associada à unidisciplinaridade vigente. (Gusdorf, 1975, p. 22-23)

Como tudo que aqui se discute se deve à questão das transformações, é fundamental a clareza de que o mundo interior das pessoas funciona como um filtro mental por onde todas as informações oriundas do mundo externo passam, antes de serem catalogadas, compreendidas e sentidas. Este mesmo filtro, que pode constituir-se no carrasco ou no libertador de cada pessoa, deve ser concebido enquanto uma resultante da biografia de cada um. Ora, se ele é um produto de construção, assim como foi produzido pode ser também desconstruído. Essa é a essência de toda transformação.

Assim, por exemplo, quando o sentimento coletivo de ser parte do grupo não mais existe, quando as pessoas se percebem como estranhos, a sociabilidade se enfraquece, fazendo surgir a indiferença, ou uma resistência passiva, um tipo de morte coletiva.

Todas essas coisas só aparecem quando se tenta apreender a cultura política presente, permeando tanto a consciência ingênua como a consciência crítica dos membros do grupo. Essa cultura se desenvolve no interior de um imaginário social que se afasta tanto das explicações mecanicistas como das racionalistas. Esse 
imaginário, como uma rede doadora de sentido, não nos oferece representações claras e distintas que possam ser tratadas pela razão analítica. Constituindo-se de crenças, mitos, ideologias, religiões e idéias, ele fala do mundo por vias oblíquas; cria novas linguagens comuns, sem necessariamente verbalizá-las. Tanto pode remeter a seus heróis mediante contos, histórias e fantasias, como em cerimoniais, rituais, danças e festas esportivas, enfim, mediante práticas sociais simbólicas. É com essas práticas que se reforçam tipos ideais de comportamento social. Os homens se reconhecem como semelhantes, como membros de uma mesma comunidade, em virtude de um cotidiano que tem também uma dimensão pré-reflexiva. A cultura política, como um saber-fazer, aposta mais no papel do enriquecimento profundo do homem do que na argumentação teórica que esse homem possa elaborar. (Ferreira, 1993, p. 223)

Deste modo, Mills compreende a imaginação sociológica como qualidade de espírito que capacita as pessoas $(a)$ a compreender o cenário histórico mais amplo, no âmbito do significado para a vida íntima e para a carreira exterior de muitos outros indivíduos; $(b)$ ter o discernimento em relação à possibilidade de aquisição de uma falsa consciência de suas posições sociais, dada a agitação de suas vidas diárias; e $(c)$ nesta agitação, buscar a estrutura da sociedade moderna dentro da qual são formuladas as psicologias de diferentes homens e mulheres. Assim, a ansiedade pessoal se focaliza sobre fatos explícitos, fazendo com que a indiferença do público se transforme em efetiva participação nas questões públicas.

Como resultado desta imaginação sociológica, surge a idéia de que a pessoa somente compreende sua própria experiência e avalia seu destino quando se localiza dentro de seu período e a clareza de que o reconhecimento de suas possibilidades de vida se dá pela conscientização das possibilidades de todas as pessoas, nas mesmas circunstâncias. Deste modo, tem-se a imaginação sociológica oportunizando a compreensão da história e da biografia, bem como suas inter-relações no seio da sociedade. (Mills, 1972, p. 11-12)

Tal conceito e sua incorporação pressupõem a formação de um formulador de perguntas-chave dotado da capacidade de passar de uma perspectiva sociológica a outra, da política para a psicológica, do estudo de uma família para análises comparativas de orçamentos nacionais, de uma escola teológica a estruturas militares, da indústria petrolífera à poesia contemporânea. Esta dinâmica intelectual permite a experienciação de uma transvalidação de valores, compreendendo então o sentido cultural da 
Ciência Social. Desta dinâmica, emerge o que possivelmente se constitua no tirocínio mais proveitoso que se obtém pela imaginação sociológica: o que distingue entre perturbações pessoais originadas no meio mais próximo e as questões públicas da estrutura social. Isto que pode ser dito como um trabalho clássico na área da Ciência Social, pode ser assim especificado:

a) as perturbações são as ocorrências no caráter do indivíduo e no âmbito de suas relações imediatas com os outros - na esfera do indivíduo elas se dão como entidades biográficas e dentro do alcance de seu meio imediato. Uma perturbação é sempre um assunto privado, ocorrendo quando a pessoa sente que os valores por ela estimados estão sob ameaça;

b) as questões dizem respeito a assuntos que transcendem aos ambientes locais do indivíduo e ao alcance de sua vida íntima. Referem-se à organização de muitos ambientes que se revelam como instituições de uma sociedade histórica, na rede dos vários ambientes de pequena escala. Uma questão é sempre um assunto público sob ameaça. Sendo o que os marxistas nominam de "contradições" ou "antagonismos", as questões passam por debates imprecisos que abordam o que o valor ameaçado re-presenta $\mathrm{e}$ o que, de fato, o ameaça. (Mills, 1972, p. 14-17)

Estes dois aspectos perceptíveis pelo exercício da imaginação sociológica favorecem a abordagem seguinte a que se propõe este trabalho, no que se refere às relações entre indivíduo e sociedade, na ótica de Mills.

\section{Mills e as relações entre indivíduo e sociedade}

Zombai, zombai, Voltaire, Rousseau! Zombai, zombai: tudo porém, em vão! Vós atirais a areia contra o vento, Eo vento a sopra em vossa direção.

(W. Blake: Mofadores)

Pelo até aqui exposto, afirmo que a preocupação central de Mills repousa diretamente sobre a necessidade de que seja difundida, pelas vias da educação e da cultura, a matriz de idéias que consagra a metáfora da rede, 
da inexistência do "eu sozinho". A rigor, tal ideomática pressupõe que não é o indivíduo o sistema, mas sim que ele se constitui em um componente de um sistema muito maior, que transcende a própria sociedade humana, pois também esta é um dos segmentos de um metassistema planetário.

Deste modo, a faculdade da imaginação sociológica permite entendimentos sempre mais apurados, que descortinam as interferências recíprocas, dialéticas, entre indivíduos e contextos; além disto, ela provoca a lembrança de que o próprio sujeito, enquanto parte sistêmica, é uma rede em si mesmo, configurando dentro de si um universo que interage com universos circundantes e, todos, retroagindo num universo maior. Sendo assim, o que se passa no mundo ocorre em mim e, se me encontro despreparado para as mudanças, se mudam as circunstâncias, que até me pareciam invariantes, minha invenção do futuro (que me determina o presente), entra em colapso. Meus valores passados não mais significam garantia alguma; meu sucesso de ontem tem suas premissas levadas a zero.

Toda crise, que é sempre multifacetada, reflete radiações emitidas de um núcleo gerador, em função de valores. Crises sempre espelham transformações valorativas, quando então sua força é inversamente proporcional à existência de novos projetos que visem uma rearticulação, uma reestruturação em bases novas. Em síntese, crise representa ausência de projetos ou transformação substantiva nos projetos em curso. Na esfera individual, a posse de projetos é a garantia de desenvolvimento equilibrado; não os ter é um caminhar para a morte. Se no passado a satisfação de necessidades básicas (biológicas e/ou econômicas) constituía-se na meta precípua a ser perseguida pela organização social, hoje se tem claro que se tais satisfações não se vinculam à possibilidade de sonhos, fantasias, planos individuais, passíveis de articulação com projetos coletivos, também nos leva a uma espécie de morte.

Em nível social, a ausência de projetos coletivos costuma constituir-se em um problema crítico, responsável pelo surgimento de neoconflitos, sobretudo em sociedades industrializadas (...). Nos países em desenvolvimento, muitas vezes, simulacros de projetos ganham corpo a partir da aspiração, quase sempre ingênua, de copiar os desenvolvidos. Nesses, a ausência de matrizes para serem copiadas, costuma conduzir a certas ilusões de rompimento com o status quo, a marginalidades fictícias, facilmente absorvíveis pelo sistema, como a dos movimentos hippies dos anos 
60. Em qualquer caso, portanto, crise sempre significa ausência ou transformação radical nos valores, ausência ou transformação radical nos projetos, tanto em nível individual, quanto em nível coletivo. (Machado, 1995, p. 301-02)

Por estas visões e análises passam, permanentemente, as dimensões de questões públicas para a coletividade e as preocupações-chave dos indivíduos.

"Para formular as questões e as preocupações, devemos indagar quais os valores aceitos e que estão ameaçados, e quais os valores aceitos e mantidos pelas tendências características de nosso período. Tanto no caso da ameaça como do apoio, devemos indagar que contradições de estrutura mais destacadas podem existir na situação." (Mills, 1972, p. 17)

Entendo ser este o fator primordial recomendado por Mills para que se cuide, nos estudos ou nas tomadas de decisão, da relação indivíduo/sociedade. Nesta linha de pensamento, o autor levanta o que pode ser denominado estados de espírito sobre a dinâmica dos acontecimentos sociais:

a) bem-estar, quando as pessoas, estimando certos valores, não sentem que sobre elas pese qualquer ameaça;

b) crise, quando os valores estimados são ameaçados, seja na perspectiva pessoal, seja enquanto questão pública;

c) pânico, quando todos os valores em jogo encontram-se ameaçados;

d) indiferença, quando as pessoas não têm consciência de valores e não se dão conta de possíveis ameaças;

e) apatia, quando a indiferença é absolutamente coletiva;

f) inquietação, quando não há qualquer consciência de valores, mas as pessoas sentem, agudamente, alguma ameaça.

Segundo Mills, encontrava-se o mundo, na década de 50, nos estados de inquietação e indiferença. Talvez como processo de èvolução destes estados, hoje percebe-se a configuração do panico, dadas as circunstâncias e a inviabilidade dos projetos, sejam individuais, sejam coletivos, em larga escala.

Porém, nossa época também tem sido marcada pela incapacidade de formular, sobre a inquietação e a indiferença, problemas que nos mobilizassem para o exercício da razão e da sensibilidade, de modo a nos afastarmos da miséria da inquietação vaga para um estágio de claras definições em termos de valores e ameaças. Menos ainda, houve qualquer formulação enquanto problemas de ciência social! 
Para os que aceitam valores herdados, como razão e liberdade, é a inquietação em si que constitui o problema; é a indiferença em si que constitui a questão. E essa condição de inquietação e indiferença é que constitui a característica marcante de nosso período. (...) ouvimos dizer, com freqüência, que os problemas de nossa década, ou mesmo as crises de nosso período passaram além do setor exterior da economia, e têm hoje relação com a qualidade da vida individual - na verdade com a possibilidade de continuar havendo, dentro em breve, qualquer coisa a que se possa chamar adequadamente de vida individual. Não o trabalho infantil, mas as histórias em quadrinho, não a pobreza, mas o ócio em massa, são os centros de preocupação. Muitas das questões públicas bem como muitos problemas privados são descritos em termos de "psiquiatria"- freqüentemente numa tentativa patética de evitar grandes questões e problemas da sociedade moderna. Tal formulação se baseia, quase sempre, num estreitamento provinciano do interesse das sociedades ocidentais, ou mesmo dos Estados Unidos - que assim ignoram dois terços da humanidade - quase sempre, também separa arbitrariamente a vida individual das grandes instituições dentro das quais ela se realiza (...). (Mills, 1972, p.18-19)

O modo como o autor destaca a exigência de produção do conhecimento, pelo uso da imaginação sociológica, sobre as relações entre os indivíduos e a sociedade, além de jogar com o tirocínio dos critérios de verdade e ordem de valores, pressupõe a noção de totalidade. Levando-se em conta que exista uma ordem no real, permanentemente sendo recriada e compondo sua própria estrutura, seu conhecimento remonta à contingência da idéia de totalidade, cujo significado pode ser aceito como a realidade como um todo estruturado, sempre dialético, no qual/do qual um fato qualquer pode vir a ser racionalmente compreendido (Kosik, 1976, p. 35). E este é um ponto sobre o qual Mills critica os intelectuais da área. 


\title{
A crítica necessária à Ciência Social contemporânea
}

\author{
Por que estás rindo? \\ A história refere-se a ti, \\ apenas o nome está mudado.
}

(Horácio, Sátiras)

A máxima de que para cada solução nos deparamos com alguns novos problemas vem sendo utilizada em escala crescente pelos que ousam também crer e dizer que a buscar maior da humanidade é apenas a felicidade.

Igualmente destacado tem sido o papel hegemônico, e de conseqüências deletérias, que o pensamento cientificista vem exercendo, há quatro séculos, no âmbito geral das ciências, destacadamente nas que tratam do entendimento dos humanos. Todos os grandes pensadores, que trazem como a marca definitiva de seu trabalho o aprimoramento humano, pautam-se por esta questão histórica:

A finalidade do desenvolvimento submete-se ela própria a outras finalidades. Quais? Viver verdadeiramente. Viver melhor: Verdadeiramente e melhor. $\mathrm{O}$ que significa isso? Viver com compreensão, solidariedade, compaixão. Viver sem ser explorado, insultado, desprezado. Significa que as finalidades do desenvolvimento dependem de imperativos éticos. O econômico deve ser controlado e finalizado por normas antropo-éticas. (Morin, 1995, p.113)

Progresso não mais se mede com índice tão simplório, insensível e desconcertante quanto o PNB. Progresso é então, algo muito mais complicado, que inclui, predominantemente, fatores que nada têm a ver com o fluxo de dinheiro e movimentação de materiais, tais como a maior disseminação da felicidade individual, melhor integração da Humanidade em seu ambiente, ambiente mais belo, mais saudável, mais rico em Vida, com Vida mais diversificada; mais estável e mais harmônica estrutura social, mais cultura, mais excelência intelectual, mais arte, recreação, intercâmbio social, mais 
alegria de vida. A ênfase está toda na qualidade, não na quantidade. (Lutzenberger, 1990, p. 47)

Quanto à ciência, que se julga no direito de nos dizer o que é verdadeiro e o que é falso, inclusive o que é justo ou injusto, bom ou mau, só pode fazer isso renunciando a ajudar-nos a decidir quanto ao que é melhor ou pior. Porque, para a conquista de seus inegáveis êxitos, ela teve que renunciar aos seus valores. (Japiassu, 1991, p. 13)

Com o velho paradigma que atomizava, contrapunha e isolava o ser humano do universo e da comunidade dos vivos, penetrara por todos os poros em nossa vida e criara uma subjetividade coletiva adequada a suas instituições, assim o novo paradigma deve também formar novas subjetividades e se introduzir em todas as instituições da existência, da sociedade, da família, dos meios de comunicação e das instituições educativas para gestar um novo homem e uma nova mulher planetários, solidários cosmicamente e sintonizados com a direção global do processo evolucionário. (Boff, 1995, p. 185)

Mills, ao discorrer sobre a ciência que projetou a bomba $\mathrm{H}$, que se tornou ambígua e ameaçadora, que tem sido gerenciada por economistas e técnicos muitas vezes atuando sem escopo ético, recoloca a Ciência Social para além do mecanismo do relógio.

Opondo-se à Ciência Social enquanto corpo de técnicas burocráticas, que se marcam pela inibição da pesquisa social em função de pretensões "metodológicas", eivadas de conceitos obscurantistas, ou que se preocupam com problemas insignificantes, isentos de relevância pública, delata a preguiçosa segurança da especialização e impõe o desafio da promessa intelectual daquele campo do saber, que implicam no uso da imaginação sociológica e no sentido político dos estudos do homem e do social.

A partir da análise do que se vem entendendo como Sociologia norte-americana, que, pretendem alguns, transformou-se em centro de interesse pelo aspecto metodológico e enquanto "teoria geral", Mills aborda as três tendências que direcionam concepções de Ciência Social, destacando seus riscos e incongruências:

a) Tendência 1 , que estaria caminhando no sentido de uma teoria da história, que faz da Sociologia um empreendimento enciclopédico, 
passível de se transformar em uma camisa-de-força transistórica, geralmente caracterizada pelo surgimento de visões profético-sombrias, muito do gênero Toynbee e Spengler;

b) Tendência 2, que se destaca no sentido de uma teoria sistemática "da natureza do homem e da sociedade". Formalismo complicado e árido, preocupado com divisões de conceitos e uma interminável predisposição que, a rigor, entende concepções enquanto conceitos. Talcott Parsons exemplifica esta linha na sociedade americana; e

c) Tendência 3, que se apresenta como estudos empíricos de fatos e problemas sociais contemporâneos, tornou-se o tema central do pensamento nos Estados Unidos, logo de início. Resulta em um praticalismo liberal, compondo um mosaico de estudos miscelâneos e restos acadêmicos, na pretensa argumentação de serem estudos de área especial da sociedade, dentro da Sociologia. Podem tornar-se uma série de fatos desconexos e com frequiência insignificantes, na medida em que se relacionam com ambientes de pequena escala. Cursos e livros didáticos bem exemplificam esta tendência.

É exemplar, dentro da perspectiva crítica de Mills, a questão dos estudos ao redor da inovação, no campo econômico, que vem sendo chamado de kanban. A rigor, segundo Coriat, para compreender o kanban, é necessário contextualizá-lo como duas das fases que levaram ao advento do toyotismo (visão de "excelência", "competência" e "qualidade total", emanadas do modelo de produção da "família" Toyota do Japão). Seriam elas:

a) primeira fase: introdução, na indústria automobilística, da experiência advinda do ramo têxtil, que reverte a concepção de especialização do trabalhador para a contingência de um só trabalhador operar, simultaneamente, várias máquinas;

b) segunda fase: busca de mecanismos que condicionam o aumento de produção sem aumento (e até eliminação) do número de empregados;

c) terceira fase: importação das técnicas de gestão dos supermercados norte-americanos, cujo modelo determina a reposição de produtos somente depois de sua venda - isto significa trabalhar com estoques mínimos ou sem eles, o que então se denomina kanban. Utilizado em alguns setores da própria Toyota desde 1962, o kanban atende uma das máximas do Sr. Toyoda, presidente - fundador da Toyota, para o qual "o ideal seria produzir somente o necessário e fazê-lo no melhor tempo". (apud Antunes, 1995, p. 24); e

d) quarta fase: expansão do método kanban para as empresas fornecedoras e terceirizadas. (Antunes, 1995, p. 23-24) 
Ora, tomada esta particularidade do modelo de abastecimento de gôndolas de supermercado que se projeta como ideário de todo um sistema de produção de modo isolado, descontextualizado na rede maior em que se situa, e aplicada a Tendência 3 de estudos sociológicos criticada por Mills, passa-se a ter (como se tem) resultados de estudos que:

a) enaltecem o kanban pela otimização do princípio de produção/ venda, principalmente em tempos de incerteza pela velocidade de mudanças de tendências na demanda - é o aforismo do "estocar é risco". Mas com esta leitura da "realidade", deixa-se de fazer lembrar que se está vivendo a maximização da idéia de que a moda, a media e a propaganda são os fatores que determinam as "necessidades" de consumo, numa perspectiva capitalista sujeita à discussão em relação à questão de valores;

b) colocam o método como válido (para o empresário), na medida em que é da essência do capitalismo o princípio de que é o investimento que gera a riqueza (e não o consumo). Mas deixa de enredar-se o kanban enquanto culminância do toyotismo, o qual responde por alguns acontecimentos significativos das profundas transformações ocorrentes na relação capital/trabalho, tais como:

1- já na década de 50, por meio da repressão, do lockout e da cooptação, principalmente a Toyota (ao instituir as palavras de ordem "Proteger nossa empresa para proteger a vida!"), a partir do ideário patronal, desmoraliza o até então combativo movimento sindicalista japonês, instituindo o sindicalismo de empresa ("sindicato-casa");

2- a subordinação operária ao "sindicato-casa", em troca da promessa de emprego vitalício, que, na verdade, nunca atingiu além de $30 \%$ dos trabalhadores do Japão, e que hoje padece os seus últimos momentos;

3- o kanban, sendo implementado simultaneamente com as políticas de just in time ("a peça necessária, na quantidade necessária, na hora necessária" para a redução de estoques), de flexibilização ("novas tecnologias que possibilitem a produção de novos modelos ou tipos, com os mesmos equipamentos e operários"), de terceirização (e quarteirização), de subcontratação, de CCQs (Círculos de Controle de Qualidade), de eliminação de desperdícios, de "gerência participativa", de sindicalismo de empresa e outros tantos mecanismos que buscam a "qualidade total", também no Japão, levou ao fenômeno do karoshi (a morte súbita no trabalho, determinada pelo ritmo e intensidade que resultam da busca interminável de aumento da produtividade). 
(...) julgamos pertinente afirmar que a "substituição" do fordismo pelo toyotismo não deve ser entendida, o que nos parece óbvio, como um novo modo de organização societária, livre das mazelas do sistema produtor de mercadorias e, o que é menos evidente e mais polêmico, mas também nos parece claro, não deve nem mesmo ser concebido como um avanço em relação ao capitalismo da era fordista e taylorista. Neste universo, a questão que nos parece mais pertinente é aquela que interroga em que medida a produção capitalista realizada pelo modelo toyotista se diferencia essencialmente ou não das várias formas existentes de fordismo. Queremos aqui tão-somente enfatizar que a referida diminuição dentre elaboração e execução, entre concepção e produção, que constantemente se atribui ao toyotismo, só é possível porque se realiza no universo estrito e rigorosamente concebido do sistema produtor de mercadorias, do processo de criação e valorização do capital. (Antunes, 1995, p. 33)

Em uma contemporaneidade cujos analistas chegam a falar de até 800 milhões de desempregados e subempregados no mundo, sem que tenham para apresentar ao público uma única alternativa de revertimento do quadro sequer (sejam eles economistas ou sociólogos), as considerações de Mills e sua exigência de imaginação sociológica parecem eivadas de cabimento, restando, sem dúvida, à Ciência Social, um repensar de caminhos e papéis.

\section{Sugestões de caminhos e tarefas básicas à Ciência Social}

Admirável mundo novo / que tem tais habitantes!

(Sheakspeare, A tempestade).

A Quarta Época. É assim que Mills nomina o que se vem conhecendo, por vezes nebulosamente, como pós-modernidade. Trata-se de uma suposição, de uma ideomática de um tempo em que mais sentimos do que racionalizamos, e sempre pela tangencialidade das consequiências das transformações que se tornam indicativos de que o que um dia era sólido esboroou-se. 
Para o autor, liberalismo e socialismo, ambos adventos do Iluminismo, não deram conta das explicações necessárias do mundo e de nós mesmos.

Em ambos a maior racionalidade é considerada como a maior condição da maior liberdade. A noção libertadora do progresso pela razão, a fé na ciência como um bem puro, a busca da educação popular e a fé no seu sentido político para a democracia - todos esses ideais do Iluminismo basearam-se sobre a suposição feliz da relação inerente da razão e liberdade. Os pensadores que fizeram mais para modelar nossas formas de pensamento, agiram com essa suposição. Ela está sob todo movimento e nuança da obra de Freud: para ser livre, o indivíduo deve tornar-se mais racionalmente consciente; a terapia é uma ajuda para dar à razão sua oportunidade para funcionar livremente no curso da vida do indivíduo. A mesma suposição sublinha a linha principal do marxismo: os homens, colhidos na anarquia irracional da produção, devem tornar-se racionalmente conscientes de sua posição na sociedade; devem tornar-se "conscientes de classe" - cujo sentido marxista é tão racionalista quanto qualquer termo exposto por Bentham. (Mills, 1972, p. 181)

Parecendo-lhe que as idéias de liberdade e razão se mostram ambíguas tanto nas sociedades capitalistas quanto nas comunistas, destaca 0 fato de que enquanto o liberalismo se comporta como uma forma trivial e irrelevante de mascarar a realidade social, o marxismo, em sua prática, mostrou-se como uma retórica em defesa do abuso burocrático.

E aqui dá-se também um encontro entre Mills e Foucault. Não por acaso, em 1975 a Gallimard publica o antológico Vigiar e punir, onde a questão do controle, da disciplina e o descortinar do princípio de Bentham, nos alertam para o fato de que o poder devia ser visivel e inverificável, por meio do qual se induz nos "detentos" um estado consciente e permanente de visibilidade que assegura o pleno e automático funcionamento do poder. É o Panóptico de Bentham:

Se os detentos são condenados, não há perigo de complô, de tentativa de evasão coletiva, projeto de novos crimes para o futuro, más influências recíprocas; se são doentes, não há perigo de contágio; loucos, não há risco de violências recíprocas; crianças, não há "cola", nem barulho, nem conversa, nem dissipação. Se são operários, não há roubos, nem conluios, nada dessas distrações que 
atrasam o trabalho, tornam-no menos perfeito ou provocam acidentes. A multidão, massa compacta, local de múltiplas trocas, individualidades que se fundem, efeito coletivo, é abolida em proveito de uma coleção de individualidades separadas. Do ponto de vista do guardião, é substituída por uma multiplicidade enumerável e controlável; do ponto de vista dos detentos, por uma solidão seqüestrada e olhada. (Ordenação de 20/03/1764)

(...) Pode-se então falar, em suma, da formação de uma sociedade disciplinar nesse movimento que vai das disciplinas fechadas, espécies de "quarentena" social, até o mecanismo indefinidamente generalizável do "panoptismo". Não que a modalidade disciplinar do poder tenha substituído todas as outras, desqualificando-as às vezes, mas servindo-lhes de intermediária, ligando-as entre si, prolongando-as, e principalmente permitindo conduzir os efeitos de poder até os elementos mais tênues e mais longínquos. Ela assegura uma distribuição infinitesimal das relações de poder. (Foucault, 1975, p. 177, 189-190)

Seja pela memória do sovietismo, seja pela análise do contex̀to em que a contribuição de Mills foi produzida, seja pela observância um pouco mais apurada do toyotismo, as metáforas foucotianas são lapidares!

Citando Mannheim, Mills resgata o conceito de auto-racionalização, por meio do qual se compreende um tempo em que o indivíduo, mergulhado nos limitados segmentos das grandes organizações racionais, passa a regular seus impulsos e aspirações, seu modo de vida e de pensamento, em irrestrita concordância com as regras e regulamentos da organização. Nasceria assim o Robô Alegre. Este o grande tema da condição humana e indicativo de estudos que se encontra no aguardo para ser transformado em problema da Ciência Social, desde os ensaios sobre a alienação de Karl Marx, desde A metrópole de Georg Simmel, ou da Grande Sociedade de Grahan Wallas, ou do autômato de Fromm, do 1984 de Orwell. Baseando-se na liberdade como preocupação, na crise da individualidade e do processo de criação da história; no papel da razão na vida individual livre, na reformulação e no esclarecimento desses problemas, Mills identifica a promessa da Ciência Social.

Seu conceito de liberdade, como sendo a possibilidade de reformular as alternativas existentes, discuti-las ao extremo e então gerar a oportunidade de escolha, é aplicável à Ciência Social frente às crescentes tendências do deteriorar qualitativo e cultural das pessoas. A permanência da indecisão, ou o reconhecimento da omissão, acarretará o ônus do cientista social vir a ser co-responsabilizado pelo advento de um admirável 
mundo novo, onde o número de $\mathrm{Alfas}^{+}$talvez se reduza, ou, quem sabe, ninguém venha a passar de um Ípsilon .

\section{Finalização}

Howard Gardner, consagrado pesquisador que se encontra abalando o mundo da Pedagogia, graças à sua divulgação sobre as múltiplas inteligências humanas, nos faz perceber que as contestações em relação à era moderna já eram notórias e contundentes no final do século XIX: os temas de decadências são centrais na vida e na obra de Oscar Wilde: o niilismo de Nietzsche assim como a quebra do status absoluto do tempo e do espaço, que veio a substituir um mundo "objetivo" newtoniano estável por um mundo relativista de Einstein, são apenas alguns indicadores sobre o tempo que demanda para as mudanças de paradigmas. (Gardner, 1996, p. 16)

Sendo assim, o manifesto de Mills, mais de quarenta anos depois, preocupa não somente pelo seu próprio contido, como pela necessária reflexão sobre as nossas resistências, sobre todo o século de mazelas e de relutância em se abandonar um modelo civilizatório que nos trouxe ao momento mais crítico de toda a história da humanidade. Salvo não passássemos de um Fausto, desempenhando o papel de peão no jogo que se trava entre Deus e o Diabo, a questão da imaginação sociológica deve ser levada ao extremo para que se revertam quadros de falha nas percepções, de postura cultural que nos tem levado a atitudes com propósitos menores e que nos cristalizam em uma visão de mundo que nos coloca em situação terminal.

Antes de tudo, a contribuição de Mills é um recado aos educadores, um norteador à construção de currículos escolares comprometidos com a formação de um novo ser humano, para um novo tempo. Para tanto, o ponto de partida parece estar no reconhecimento, na aceitação de que, há muito, encontramo-nos em rota de colisão com um futuro que nos tem enviado mensagens alarmantes.

Filhos de uma cultura centrada na produção, é ela que nos norteia em todas as ações: trabalhamos para atingir objetivos (nossos ou de alguém), descansamos tendo em vista a recuperação de nossas energias; não comemos, simplesmente ingerimos alimentos nutritivos, não jogamos apenas com nossos filhos, preparamo-los para "um futuro". Com isso, não estabelecemos relações, pois estamos tão preocupados com as conseqüências que não vemos o outro como partícipe efetivo de um encontro, não 
percebemos as circunstâncias em que este ocorre, ou não nos vemos nunca com o outro. (Maturana; Verden-Zöllar, 1994, p. 88)

Mills faculta encontros; encontros entre o leitor e outros que se escrevem; encontros com a reflexão que transcende os limites estreitos do "eu" projetando-nos nas biografias e na história. A elegância e a forma ao mesmo tempo contundente com que questiona a produção do conhecimento, reforça a hipótese de que, possivelmente, no começo, não foi o verbo: no início, era a relação. E então, com Mills e Moreno, finalizo imaginando que a vida seja toda feita de (re)encontros.

\section{RESUMO}

O que se vem chamando de "pós-modernidade" reflete, na essência de suas crises, o profundo caráter de resistência oferecida à necessidade de mudanças profundas nas atitudes, na percepção e na visão de mundo das pessoas em geral e dos acadêmicos em especial. A partir de contribuição de C. W. Mills, na qual o autor questiona vigorosamente o desempenho da Ciência Social, pela complementação de pensamentos de outros autores contemporâneos, busca-se levar o pano de fundo à instância da Educação, tendo em vista o favorecimento do ato educativo para um outro homem, para um novo tempo.

\section{REFERÊNCIAS BIBLIOGRÁFICAS}

ANTUNES, R. Adeus ao trabalho? Ensaio sobre as metamorfoses e a centralidade do mundo do trabalho. São Paulo: Cortez, 1994.

BOFF, L. Ecologia. Grito da terra, grito dos pobres. São Paulo: Ática, 1995.

CAPRA, F. O ponto de mutação. A ciência, a sociedade e a cultura emergente. São Paulo: Cultrix, 1988.

FERREIRA, N. Cidadania. Uma questão para a educação. Rio de Janeiro: Nova Fronteira, 1993.

FOUCAMBERT, J. A leitura em questão. Porto Alegre: Artes Médicas, 1994.

FOUCAULT, M. Vigiar e punir. História da violência nas prisões. Petrópolis: Vozes, 1987.

GARDNER, H. Mentes que criam. Uma anatomia da criatividade observada através das vidas de Freud, Einstein, Picasso, Stravinsky, Eliot, Graham e Gandhi. Porto Alegre: Artes Médicas, 1996. 
GUSDORF, G. Prefácio. In: JAPIASSU, H. Interdisciplinaridade e patologia do saber. Rio de Janeiro: Imago, 1975, p. 7-27.

HOBSBAWN, E. Era dos extremos. O breve século XX. 1914-1991. São Paulo: Companhia das Letras, 1995.

JAPIASSU, H. As paixões da ciência. São Paulo: Letras \& Letras, 1991. . Interdisciplinaridade e patologia do saber. Rio de Janeiro: Imago, 1975.

KOSIK, K. Dialética do concreto. Rio de Janeiro: Paz e Terra, 1976.

LÉVY, P. As tecnologias da inteligência. O futuro do pensamento na era da informática. Rio de Janeiro: Ed. 34, 1993.

LUTZENBERGER, J. Gaia. O planeta vivo (por um caminho suave). Porto Alegre: L \& PM, 1990.

MACHADO, N. J. Epistemologia e didática. As concepções de conhecimento e inteligência e a prática docente. São Paulo: Cortez, 1995.

MATURANA, H.; VERDEN-ZÖLLER, G. Amor y juego. Fundamentos olvidados de lo humano desde el patriarcado a la democracia. Santiago: Instituto de Terapia Cognitiva, 1994.

MILLS, C. W. A imaginação sociológica. Rio de Janeiro: Zahar, 1972.

MORIN, E. A. A construção da sociedade democrática e o papel da educação e do conhecimento para a formação do imaginário do futuro. In: GROSSI, E. P.; BORDIN, J. Construtivismo pós-piagetiano. Um novo paradigma sobre a aprendizagem. Petrópolis: Vozes, 1993, p.11-25.

; KERN, A. Terra-patria. Porto Alegre: Sulina, 1995.

VIZIOLI, P. William Blake. Poesia e prosa selecionadas. São Paulo: Nova Alexandria, 1992.

WATZLAWICH, P. (org.) A realidade inventada. Campinas: PSY II, 1994. 